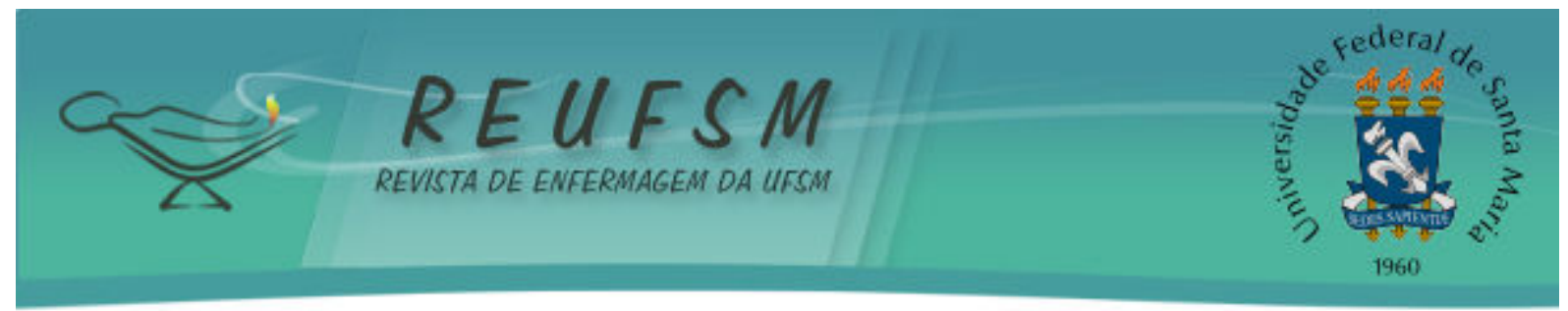

ARTIGO ORIGINAL

\title{
FATORES QUE OBSTAM NA COMUNICAÇÃO ENTRE PAIS E FILHOS ADOLESCENTES SOBRE SEXUALIDADE
}

\section{FACTORS THAT STAND IN THE WAY OF THE COMMUNICATION BETWEEN PARENTS AND TEENAGERS ABOUT SEXUALITY}

\section{FACTORES QUE DIFICULTAN LA COMUNICACIÓN ENTRE PADRES Y ADOLESCENTES SOBRE LA SEXUALIDAD NIÑOS}

\author{
Mariana Aparecida Costa ${ }^{1}$ \\ Natália Silva Rabelo ${ }^{2}$ \\ Isabela Cristina Martins Moraes ${ }^{3}$ \\ Fernando Carvalho de Macedo Siqueira ${ }^{4}$ \\ Elen Soraia Menezes Cabral $^{5}$
}

Doi: $10.5902 / 2179769210216$

RESUMO: Objetivos: analisar fatores que interferem na comunicação sobre sexualidade entre pais e filhos adolescentes em situação de vulnerabilidade social. Método: utilizou-se a abordagem qualitativa e a dialética como referencial teórico filosófico. No tratamento e avaliação dos dados coletados utilizou-se a Análise de Conteúdo. Resultados: a comunicação no âmbito familiar frequentemente está ausente ou é insuficiente. Certos pais revelaram que apesar dos entraves, abordam o assunto, dando margens a superações. Considerações finais: objetivando superar as dificuldades e contradições entre pais e filhos adolescentes sobre sexualidade, sugerimos o apoio de profissionais de educação e de saúde na utilização de estratégias, que considerem os modos de vida juvenis. A existência de diálogo aberto, democrático, livre de coerções e de preconceitos é essencial para a redução da vulnerabilidade do adolescente intrínseca à comunicação ineficaz sobre sexualidade.

Descritores: Adolescente; Pais; Sexualidade; Comunicação.

ABSTRACT: Aim: to analyze factors which interfere in the communication about sexuality between parents and teenagers in situation of social vulnerability. Method: it was used the qualitative approach and the dialectics as philosophical theoretical reference. In the study and assessment of the collected data we used Content Analysis. Results: the communication within the family is often absent or insufficient. Some parents revealed that despite the obstacles, they broach the subject in order to make easy the overcoming. Final Thoughts: aiming to overcome the difficulties and contradictions between parents and teenagers about sexuality, we suggest the support of professionals in education and health in the use of strategies that consider the juvenile lifestyles. The existence of an open, democratic, free of coercion and prejudice dialogue is essential to the reduction of the adolescents' vulnerability inherent in the ineffective communication about sexuality.

Descriptors: Adolescent; Parents; Sexuality; Communication.

\footnotetext{
${ }^{1}$ Enfermeira. Graduada em Enfermagem pela Universidade Federal de São João Del-Rei, Campus Centro-Oeste Dona Lindu. Divinópolis/MG, Brasil. Email: maricosta.ufsj@yahoo.com.br

${ }^{2}$ Enfermeira. Graduada em Enfermagem pela Universidade Federal de São João Del-Rei, Campus Centro-Oeste Dona Lindu. Divinópolis/MG, Brasil. Email: nataliarabelo@hotmail.com

${ }^{3}$ Enfermeira. Graduada em Enfermagem pela Universidade Federal de São João Del-Rei, Campus Centro-Oeste Dona Lindu. Divinópolis/MG, Brasil. Email: belasorrisomoraes@hotmail.com

${ }^{4}$ Enfermeiro. Graduado em Enfermagem pela Universidade Federal de São João Del-Rei, Campus Centro-Oeste Dona Lindu. Divinópolis/MG, Brasil. Email: ferdynando@oi.com.br

${ }^{5}$ Enfermeira. Mestre em Enfermagem pela Universidade Federal de Minas Gerais,UFMG. Professora Assistente da Universidade Federal de São João Del-Rei, Campus Centro-Oeste Dona Lindu. Divinópolis/MG, Brasil. Email: elenmenezesc@gmail.com
} 


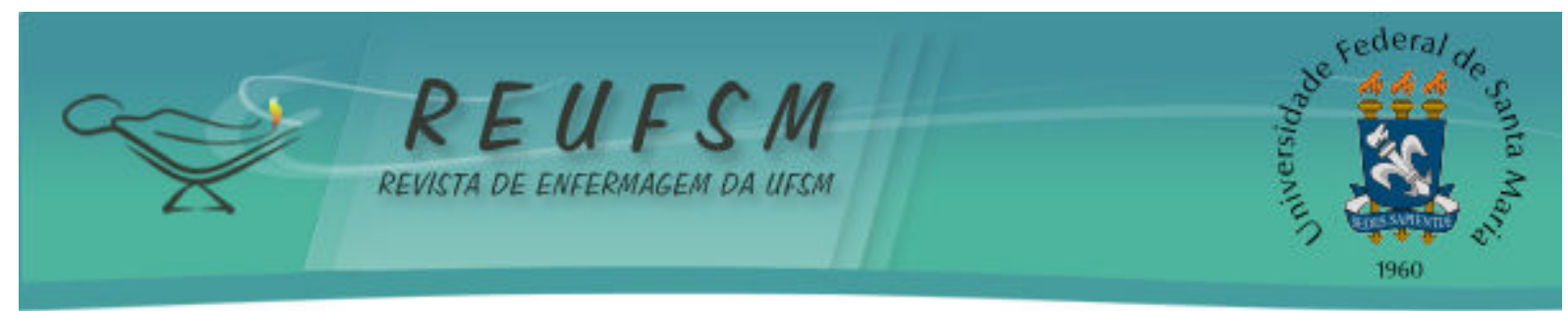

RESUMEN: Objetivos: analizar los factores que interfieren en la comunicación acerca de la sexualidad entre padres e hijos adolescentes en situación de vulnerabilidad social. Método: fue utilizado el abordaje cualitativo y la dialéctica como referencial teórico filosófico. Para el tratamiento y evaluación de los datos recogidos usamos análisis de contenido. Resultados: la comunicación en el ámbito familiar a menudo está ausente o es insuficiente. Algunos padres revelaron que pesar de los obstáculos, abordan el tema, dando margen a las superaciones. Consideraciones finales: con el objetivo de superar las dificultades y contradicciones entre padres e hijos adolescentes acerca de la sexualidad, sugerimos el apoyo de profesionales de educación y de salud en el uso de estrategias que consideren los modos de vida juveniles. La existencia de diálogo abierto, democrático, libre de coerción y de prejuicios es indispensable para reducir la vulnerabilidad adolescente intrínseca a la comunicación ineficaz sobre sexualidad.

Descriptores: Adolescente; Padres; Sexualidad; Comunicación.

\section{INTRODUÇÃO}

A sexualidade é algo que se constrói e se aprende socialmente. Ela é ampla, difusa, complexa e fundamental no desenvolvimento da personalidade. Nas sociedades ocidentais foi, historicamente, estruturada, cercada por mitos e tabus os quais muitas vezes, na atualidade, se impõem como obstáculos à felicidade das pessoas. A vivência insatisfatória da sexualidade pode interferir no processo de aprendizagem, nos relacionamentos, na saúde mental e física dos sujeitos.

Diferentes grupos demandam questões diversas nessa temática, mas quando se trata de adolescentes, as dificuldades de comunicação apresentadas por pais, educadores e profissionais de saúde são potencializadas pelo despreparo dos adultos em lidar com as especificidades dos jovens. Há ainda, o atravessamento de visões preconceituosas, atitudes impositivas e o não reconhecimento das necessidades e autonomia dos adolescentes. ${ }^{1}$ No entanto, sabe-se que um dos direitos que os jovens mais defendem quando podem se expressar livre de coerções é relativo à autonomia no âmbito da sexualidade. ${ }^{2}$

$\mathrm{Na}$ adolescência, o corpo torna-se "genitalizado". Ocorre, então, o despertar para a sexualidade, coincidindo com profundas alterações hormonais, anatômicas, fisiológicas, psicológicas e sociais. ${ }^{3-4}$ As mudanças corporais trazem consigo curiosidade e desejos, vergonha, dúvidas, medos e angústias. ${ }^{1-2-3,5}$ Essas questões intrínsecas da adolescência mostram que esses sujeitos são altamente vulneráveis às doenças ou eventos inesperados, relacionados à sexualidade.

A vulnerabilidade é entendida como o conjunto de fatores de natureza biológica, epidemiológica, social e cultural, que tem influência no risco ou proteção de uma pessoa por uma determinada doença ou dano. Pessoas susceptíveis a este fenômeno são sujeitos inaptos, de forma relativa ou absoluta, de proteger seus próprios interesses. ${ }^{6}$ Adolescentes em vulnerabilidade social estão em situação de maior desvantagem, devido à indisponibilidade dos recursos materiais e o acesso à estrutura de oportunidades sociais, econômicas e culturais fornecidas pelo Estado e sociedade. ${ }^{7}$ Há implicações do tipo de comunicação estabelecida entre pais e filhos sobre sexualidade, relativas a comportamento de risco dos adolescentes, nível de sucesso de suas escolhas, autocuidado em saúde e reprodução. 0 exposto evidencia a relevância e a necessidade de estudos que tratem o tema comunicação entre pais e filhos adolescentes em vulnerabilidade social. ${ }^{6}$

A comunicação ineficaz entre pais e filhos, acerca da sexualidade, é preocupante, pois pode colaborar para o aumento da vulnerabilidade dos jovens na medida em que se perde uma oportunidade privilegiada para informar adequadamente, sobre sexo seguro e os riscos de gravidez não planejada, infecção por Doenças Sexualmente Transmissíveis (DSTs) e AIDS. Além disso, na busca de uma identidade própria, o ser adolescendo apoia-se 


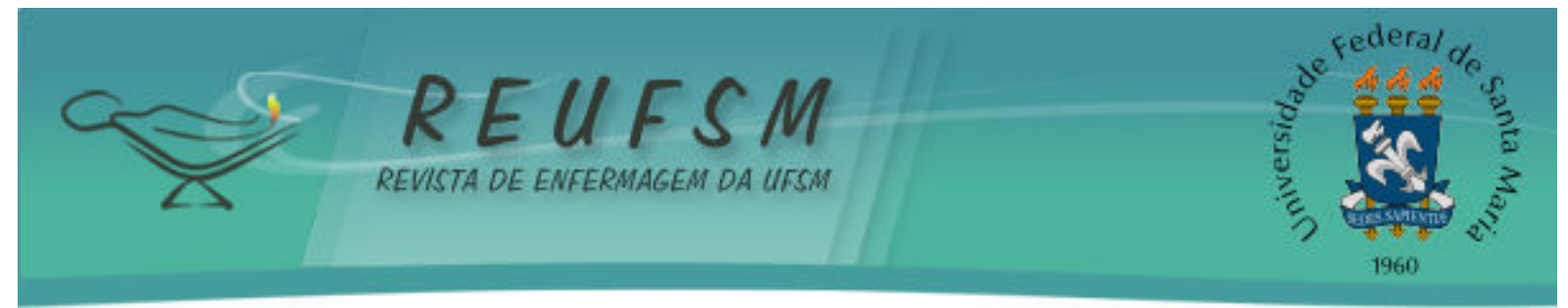

nas primeiras relações afetivas que teve com seus familiares e sabe-se que o nível de educação, a condição socioeconômica, a qualidade da relação familiar, os valores parentais face aos comportamentos sexuais e a comunicação entre pais e filhos estão entre as características familiares que mais influenciam comportamentos sexuais dos jovens. ${ }^{8-9}$

No entanto, na adolescência, o relacionamento familiar torna-se mais distante ${ }^{10}$, e os pais nem sempre estão preparados para abordar o assunto com seus filhos. ${ }^{11-12}$ Assim, o adolescente entra em conflito com instituições e pessoas com as quais tinha um convívio harmônico, entre esses, os pais. Desta forma, os silenciamentos, as mensagens veladas e ambíguas, as imposições por parte dos pais interferem negativamente na vivência da sexualidade de seus filhos.

Em face da relevância do tema abordado, o presente estudo foi desenvolvido com o objetivo de analisar fatores que interferem na comunicação sobre sexualidade entre pais e filhos adolescentes em situação de vulnerabilidade social.

\section{MÉTODO}

Optou-se pela abordagem qualitativa que trabalha com o universo de significados, motivos, crenças, valores, atitudes, e é capaz de interpretar aspectos complexos do comportamento do ser humano. ${ }^{13}$ Foi utilizado o referencial teórico filosófico da dialética, no qual a relação do sujeito com o objeto é marcada por interesses e lutas sociais do seu tempo, considera os conflitos que as perpassam em movimentos contínuos de superação das contradições pela práxis..$^{13-14}$

Essa pesquisa foi realizada na Escola Municipal Dona Maria Rosa, situada em área de vulnerabilidade social, na periferia de Divinópolis-MG, durante os meses de novembro de 2012 a janeiro de 2013. Os participantes totalizaram oito jovens com idade entre 13 e 18 anos e seus respectivos, pai e/ou mãe, totalizando 16 sujeitos.

Os critérios para inclusão no estudo foram estudantes adolescentes do $7^{\circ}$ ao $9^{\circ}$ ano do ensino fundamental da escola citada acompanhados de pelo menos um de seus pais. E os critérios de exclusão foram os pais que não aceitaram e autorizaram a sua participação e de seus filhos na pesquisa e estudantes com idade menor que 13 anos de idade que frequentavam séries inferiores ao $6^{\circ}$ ano do ensino fundamental.

A coleta foi norteada pela pergunta aberta: "Na sua opinião, quais fatores interferem em sua comunicação sobre sexualidade com seu filho/seus pais?". A entrevista foi realizada individualmente tanto para os pais, quanto para os filhos. Um pequeno número de adolescentes foram entrevistados na referida escola e devido ao período da coleta corresponder a época das férias escolares, a maioria das entrevistas dos sujeitos de pesquisa (pais e filhos) foram previamente agendas por telefone e realizadas na casa dos próprios participantes. A coleta de dados foi feita separadamente com cada participante, sendo gravado as suas falas e após transcritos na íntegra. Para o encerramento das entrevistas utilizou-se a saturação de dados. ${ }^{15} \mathrm{O}$ material colhido foi submetido à análise de conteúdo ${ }^{16}$, e as falas analisadas foram divididas em categorias: vergonha, machismo, contradições entre pais e filhos, superação das dificuldades.

O estudo considerou todos os aspectos éticos da Resolução 196/96 do Conselho Nacional de Saúde, respeitando: anonimato, privacidade, participação voluntária e direito de desistência de participação. O Comitê de Ética em Pesquisa da Universidade Federal de São João Del Rei, Divinópolis - MG aprovou essa pesquisa sob o parecer $n^{\circ} 128.701 \mathrm{em}$ $23 / 10 / 2012$, CAAE $n^{\circ} 08123612.6 .0000 .5545$. Identificou-se os sujeitos pela letra inicial de cada categoria: A - adolescente, $M$ - mãe, $\mathrm{P}$ - pai, numeradas pela ordem da entrevista. 


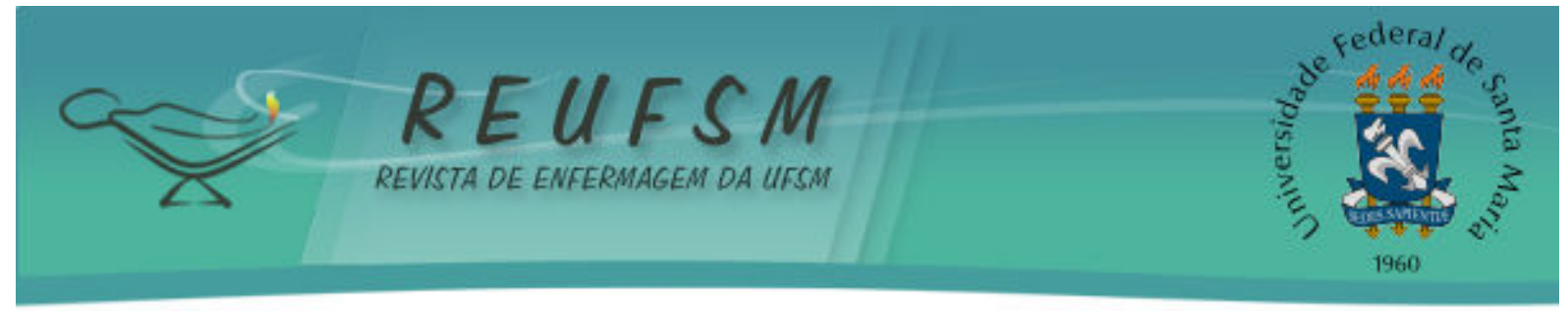

\section{RESULTADOS E DISCUSSÃO}

Na sociedade contemporânea subjaz a ideia de que a família é o melhor local para o adolescente dialogar, questionar, ser esclarecido, confidenciar suas experiências, desejos e escolhas. ${ }^{2}$ Mas isto, nem sempre, é verdadeiro e, muitas vezes, a comunicação familiar é ineficaz. Ao discorrer sobre os fatores que interferem na comunicação entre pais e filhos sobre sexualidade, os sujeitos dessa pesquisa explicitaram sobremaneira os aspectos dificultadores dessa comunicação.

\section{Vergonha}

A categoria de maior incidência nas falas dos dois tipos de sujeitos foi a vergonha. Sabe-se que os aspectos culturais, a vergonha e o preconceito são barreiras para o diálogo. ${ }^{12}$

Os pais desse estudo expressaram a vergonha que sentem e creem que seus filhos tenham como dificultador da comunicação.

Tenho vergonha de falar sobre esse assunto. Só a vergonha mesmo. (M7)

Esse sentimento pode reduzir as possibilidades de esclarecimentos de dúvidas dos adolescentes e criar um distanciamento na relação familiar. Todavia, nem sempre os pais se sentem aptos para abordar o assunto porque também não receberam informações suficientes como pode ser notado na fala:

[...] no meu tempo as coisas sobre sexualidade era uma coisa assim, que nossos pais não conversavam com agente né?! (M1)

Isso leva à perpetuação de desinformação e comunicação familiar ineficiente, e coaduna os achados de outros autores ao afirmarem que mesmo realizando seu papel de orientadora, muitas famílias falham em prestar esclarecimentos porque os adultos também não receberam informações suficientes e pela própria questão cultural. ${ }^{17}$

Quando surge um diálogo permeado pela vergonha é importante pensar na qualidade do mesmo, uma vez que esse sentimento se impõe como um óbice para a comunicação.

Eu converso bastante com ela, mas eu tenho um pouco de vergonha, né. (M5)

Diante da vergonha, os pais tendem a resumir suas orientações em recados dados de maneira indireta, às vezes, até enigmática, dificultando a compreensão pelos filhos:

[...] ó minha filha cuidado sabe, porque depois pode acontecer isso ou aquilo, então o mundo aí fora hoje tá muito moderno. (M1)

Os pais também percebem a vergonha que seus filhos sentem na abordagem do tema sexualidade como um dificultador, mas na íntegra desses discursos, não surgiu nenhuma relação desse sentimento filial com o seu papel parental.

É porque tem vergonha né, de responder... A gente pergunta ele... Fala e ele fica caladinho ele não gosta de responder. Ele tem vergonha mesmo. (M4) 


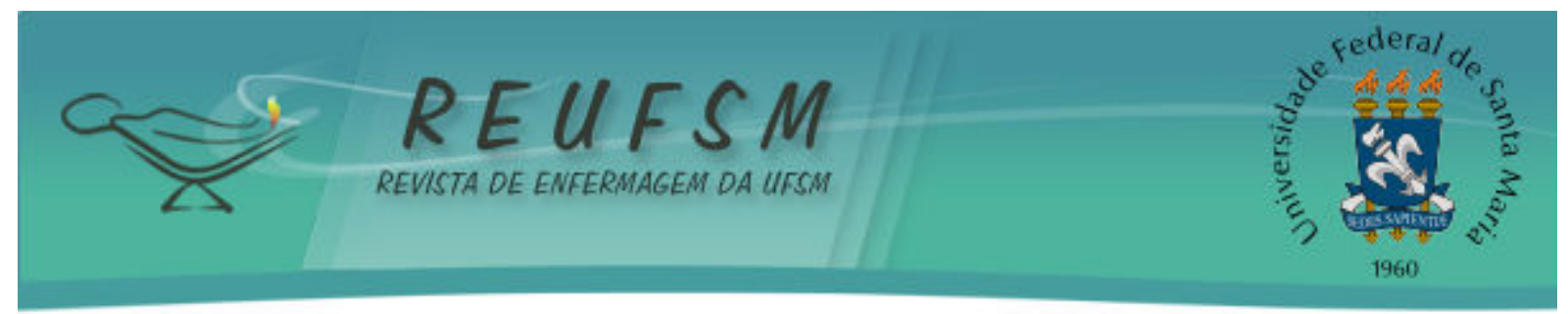

Ela tem medo, vergonha... (M8)

Essas mães parecem esperar a aproximação de seus filhos para o diálogo sobre sexualidade de maneira natural. Todavia, como a vergonha fala de algo constrangedor, pode-se inferir que em algum momento da relação, e de forma velada, o assunto tenha sido tratado como um tabu, algo a ser silenciado.

Dos adolescentes, a maioria citaram a vergonha como o principal dificultador. 0 discurso na íntegra do sujeito A6 se resumiu em uma frase sobre ela, o que demonstra o quanto esse sentimento é forte para ele.

A vergonha. Não, só a vergonha mesmo. (A6)

A relevância desse sentimento é manifestada também por A5 que informa ser ela um empecilho para o diálogo com sua mãe.

$A i$, eu nunca falei nada com ela, eu tenho vergonha, ah o que atrapalha é a vergonha. (A5)

A inexistência do diálogo entre pais e filhos pode impactar negativamente na sexualidade do adolescente, pois eles tendem a suprir essa falta esclarecendo dúvidas na internet, em revistas para o público juvenil, com seus pares ou até com desconhecidos.

Às vezes a timidez, de perguntar ou uma dúvida que eu tenho, aí eu prefiro tirar com uma pessoa, sei lá, desconhecida, ou que não tenha contato com minha mãe. (A3)

Entende-se que a busca de informações com fontes não seguras pode colaborar para uma visão distorcida sobre a sexualidade e a não aquisição de hábitos de prevenção da AIDS, DST e gravidez. ${ }^{12}$ Ressaltamos também, como consequência dessa ausência, a perda de oportunidade para o convívio, afetividade e intimidade familiar.

Percebe-se também que, para alguns sujeitos, a vergonha está atrelada à falta de intimidade, outro dificultador da comunicação:

[...] Não eu acho que é mais é isso mesmo, é a vergonha de falar assim abertamente, a forma que penso ou a forma adulta que eu tenho. (A3)

Acho que o fato de eu não ter, intimidade com minha mãe, não poder conversar com ela sobre essas coisas, porque eu acho que tenho vergonha, assim, de conversar com ela. (A4)

Estão imbricadas com a intimidade, os sentimentos de liberdade, confiança, afeto. A falta de reconhecimento da autonomia do adolescente ou de sua capacidade de entendimento pelos pais podem colaborar para a superficialidade do diálogo, como nos fala A1:

[...] Às vezes ela [mãe] acha que eu não... Posso até não entender direito, essas coisas. $O$ que impede da gente ter um diálogo mais profundo... Sobre isso é isso aí mesmo. (A1)

Da mesma forma, a convicção dos adultos de que os filhos não querem dialogar sobre sexualidade com os pais, pode obstaculizar este diálogo. 


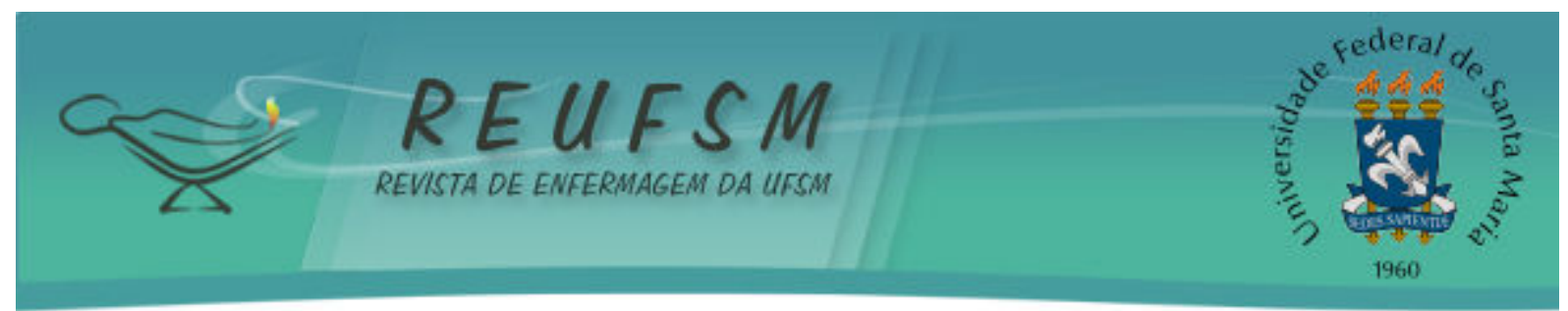

[...] Mas, quem disse que eles [adolescentes] querem saber sobre isso [diálogo com os pais sobre sexualidade]? (P6)

Não obstante o fato da família ser considerada pela sociedade um local confiável para expor questões íntimas, alguns jovens preferem buscar informações até com desconhecidos, como citado anteriormente, ao invés de fazê-lo com seus familiares.

[...] Quem conversa assim mais comigo são gente de fora, não são meus pais (A1)

[...] Elas [as jovens] acham mais fácil conversar com uma amiga, com um amigo do que com a gente [os pais]... (P6)

A adolescência é uma fase de efervescência de conflitos e contradições. Percebese em muitas falas dos sujeitos, a contradição entre os papéis de apoio, segurança e confiança esperadas da família em relação ao adolescente e tendência de afastamento do jovem de seus pais.

[...] Tenho vergonha assim de conversar com ela... Mais um medo, tipo, dela ficar com raiva de mim, alguma coisa assim. (A4)

[...] Eu também não gosto muito de conversar muito com ela, que ela é estressada demais e dá medo né de me xingar. (A8)

Nessas falas, os sujeitos expressam medo de represálias dos pais, temem decepcioná-los, e que suas ideias e atitudes não sejam aceitas pelos mesmos. Sabe-se que o diálogo permeado por uma postura repressiva dos pais sobre as questões relativas à sexualidade pode, por vezes, desencadear conflitos e até intimidar os adolescentes a procurar, na própria família, informações, por medo suscitarem nos pais um sentimento de desaprovação e até punições. ${ }^{18}$

\section{Machismo}

Dentre as posturas repressivas, o machismo destacou-se nas falas dos sujeitos.

[...] Eu acho que um irmão mais velho tem toda liberdade como homem. (M1)

[...] Igual o povo fala, hoje as meninas de hoje tá de chacota e eu não quero isso pra minha filha não sabe? (M1)

[...] Na minha opinião...Por eu ser menina, eu acho que necessitava dela [mãe] falar... (A2)

Perpetua-se na sociedade moderna, a cultura de submissão feminina. Autores evidenciam que a criação entre filho/filha é diferenciada pelos pais. ${ }^{18} \mathrm{~A}$ mãe costuma ser responsável pelo preparo de suas filhas adolescentes para a sexualidade, controlá-las e mantêlas virgens. Esse diálogo com o pai quase não ocorre, sendo evitado ou até mesmo escondido. Esta inexistência do diálogo entre pai e filha é explicitada na fala da adolescente A1. 


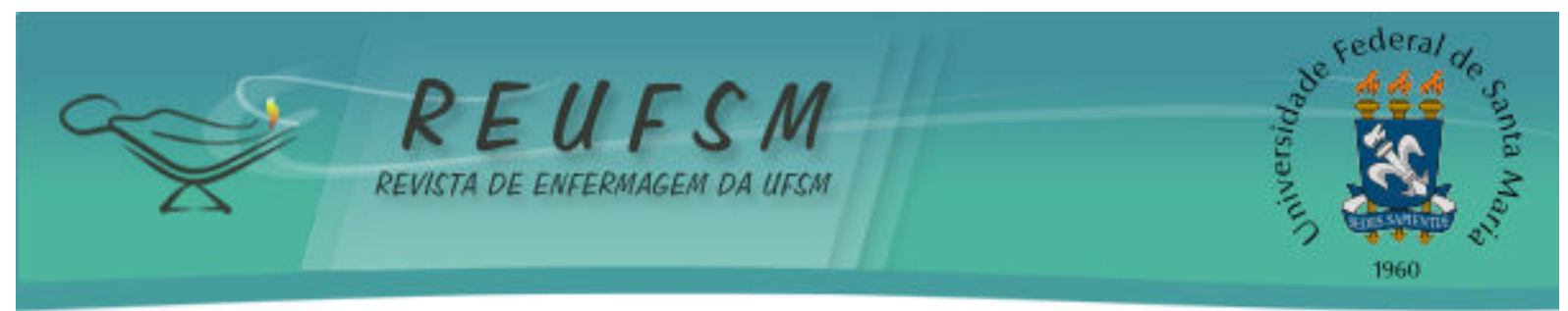

[...] Ainda mais meu pai...Ele é muito ignorante sabe, não sabe conversar comigo sobre essas coisas. (A1)

Já o ser adolescente do sexo masculino é quase sempre influenciado e motivado à prática precoce do sexo pelo pai e amigos, como prova de sua masculinidade. ${ }^{18}$ Percebese nesse comportamento uma dicotomia entre o ser homem e ser mulher. Outras contradições são facilmente percebidas nas falas dos sujeitos.

[...] A minha mãe já é um pouco diferente [do pai], porque eu chego nela e falo algumas coisas... Mas também ela não sabe conversar comigo, não leva isso a diante, não conversa. Ela sempre procura mudar de assunto. (A1)

[...] Eu prefiro tirar [dúvidas] com uma pessoa desconhecida, ou que não tenha contato com minha mãe... Mas na maioria das vezes a gente conversa muito, ela [mãe] me conta as coisas, eu falo as coisas pra ela... (A3)

[...] Eu não vejo dificuldade de conversar com ela [filha]... mas que tem, tem. (M2)

\section{Contradições entre pais e filhos}

Um fator importante, observado durante a entrevista com os sujeitos, foi a presença de contradições entre as falas dos pais e seus respectivos filhos, onde um afirma e outro nega a mesma circunstância no diálogo entre ambos.

A2 afirma que nunca conversou sobre sexualidade com seus pais:

[...] Eu nunca conversei com minha mãe sobre sexo, na minha vida até hoje. (A2)

Contradizendo a afirmação da filha, a mãe expressa:

[...] Porque eu e ela somos bem abertas em questão de conversar sobre sexualidade, eu converso muito com ela sobre isso, tanto ela comigo. (M2)

Pode-se inferir que embora o diálogo sobre sexualidade ocorra no âmbito familiar não apresenta o mesmo significado para os sujeitos. Sendo essa conversa suficiente e satisfatória na percepção da mãe e inexistente na visão da filha.

\section{Superação das dificuldades}

Apesar de serem muitas as dificuldades reveladas, há evidências de superação de algumas, como demonstrado por M5.

Eu converso bastante com ela, mas eu tenho um pouco de vergonha, né... Mas assim, eu converso bastante com ela. (M5) 


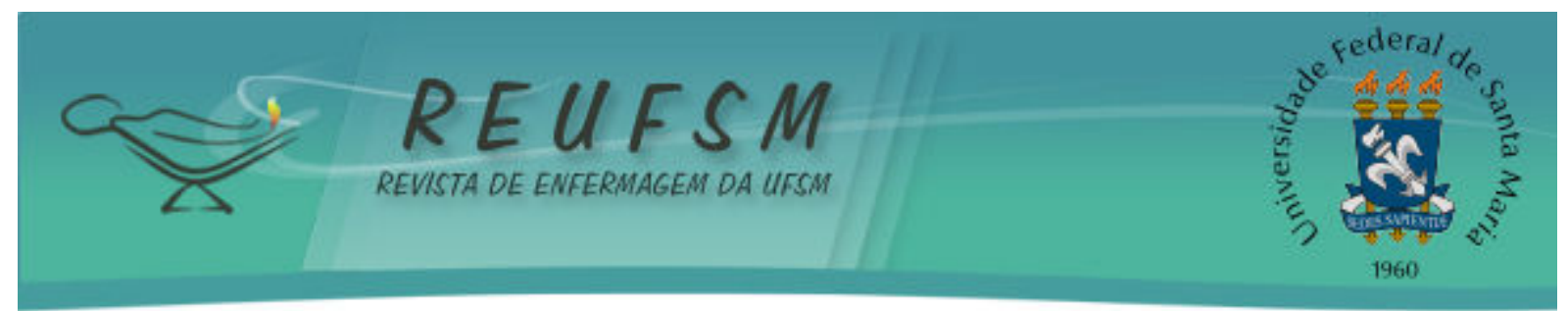

Embora não tenha ocorrido concordância quanto à existência de um diálogo satisfatório em nenhum binômio pai ou mãe/adolescente, alguns fatores facilitadores foram citados, porém de forma bem menos expressiva. Isso justifica parcialmente a escolha dos óbices ao diálogo para a análise realizada nesse trabalho. Todavia, acreditamos que estes facilitadores devem ser mencionados, pois exemplos exitosos podem respaldar atitudes positivas.

Dentre os pais entrevistados, quatro disseram manter um diálogo aberto com seus filhos sobre sexualidade. 0 que pode ser parcialmente visto nestas frases:

[...] Eu sou mais aberta, eu pergunto, converso, dou conselhos... (M4)

Eu converso bastante com ela. (M5)

[...] Eu só converso com ela de acordo com a idade, como eu tenho outra filha menor. As coisas vão acontecendo, as dúvidas aparecendo e eu vou esclarecendo de forma adulta... (M3)

Quando o diálogo é estimulado pelos pais, os adolescentes vêm na família, um meio seguro e confiável, para se apoiar e manter relações afetivas, por se sentirem acolhidos e compreendidos.

\section{CONSIDERAÇÕES FINAIS}

Depreende-se desta pesquisa, que o diálogo entre pais e filhos sobre sexualidade está permeado por variadas dificuldades e contradições, que vão desde questões culturais e intrínsecas à adolescência até aquelas de ordem estritamente pessoal. Já as facilidades foram pouco citadas. Isso demonstra que o tema abre um leque de possibilidades de trabalho para todos aqueles empenhados na lida cotidiana com adolescentes e na superação de óbices relacionados às dimensões da sexualidade dos jovens.

Destaca-se que a comunicação entre pais e seus filhos adolescentes pode ser facilitada e apoiada por profissionais de educação e de saúde. Essa colaboração pode ocorrer em várias frentes como a saúde na escola e atividades de promoção à saúde elaboradas pelas equipes de saúde da família.

Para lidar com dimensões da sexualidade dos jovens é imperioso colocar de lado os preconceitos e que o diálogo seja francamente aberto, democrático e livre de coerções. Recomendamos que a família e profissionais atuantes na educação escolar ou na saúde procurem abordar a temática considerando as dimensões mais próximas do jovem como aquelas ligadas à afetividade, autonomia, respeito. Pode se utilizada como meio de tratar o assunto, a educação continuada, em forma de palestras, gincanas e brincadeiras tanto nas unidades de saúde, como nas escolas, de maneira que possa vir a ajudar nesse convívio familiar.

Mediante a amplitude e relevância desse assunto, o desenvolvimento de novas pesquisas mostra-se essencial, a fim de discutir problemáticas afins e levantar outros recursos para consolidação de um diálogo satisfatório sobre sexualidade no contexto familiar.

\section{REFERÊNCIAS}

1. Soares CB. Mais que uma etapa do ciclo vital: a adolescência com um construto social. In: Borges ALV, Fujimori E, organizadores. Enfermagem e a saúde do adolescente na atenção básica. São Paulo: Manole; 2009. p. 3-22. (Série Enfermagem). 


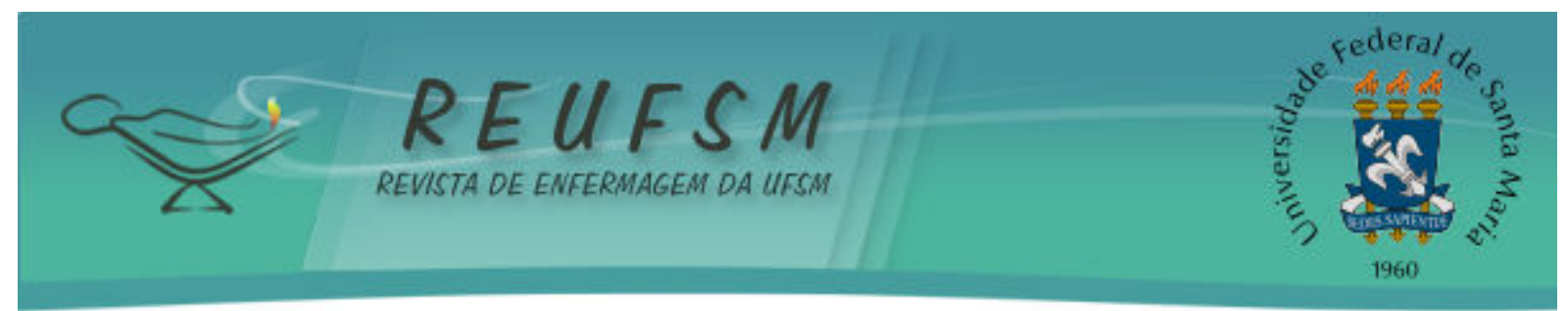

2. Castro MG, Ribeiro IR. Adolescentes, jovens, direito e família: questionando saberes sobre proteção a direitos sexuais e reprodutivos. In: Dayrell J, Moreira MIC, Stengel M, organizadores. Juventudes contemporâneas: um mosaico de possibilidades. 1a ed. Belo Horizonte (MG): Editora PUCMINAS; 2011. v. 1, p. 251-72.

3. Moraes LASS. Processo de construção da identidade do adolescente na contemporaneidade: contribuições da escola [dissertação]. Belo Horizonte (MG): Pontifícia Universidade Católica de Minas Gerais; 2011. 89 p.

4. Núcleo de Estudos da Saúde do Adolescente (NESA-UERJ). Adolescência e juventude sumário [Internet]. Rio de Janeiro. [acesso em 2011 out 31]. Disponível em: http://portal.saude.gov.br/portal/arquivos/multimedia/adolescente/adolejuventu2.swf.

5. Ergün S, Conk Z. Effect of individualized education efforts by a nurse to increase selfcare capacity in adolescents. Acta Paul Enferm. 2011;24(6):821-7.

6. Pessalacia JDR, Menezes ES, Massuia D. A vulnerabilidade do adolescente numa perspectiva das políticas de saúde pública. Rev Bio\&Thikos (Centro Universitário São Camilo). 2010;4(4):423-30.

7. Morais NA de, Koller SH, Raffaelli M. Eventos Estressores e Indicadores de Ajustamento entre adolescentes em Situação de Vulnerabilidade Social no Brasil. Universitas Psychologica [Internet]. 2010 [acesso em 2011 nov 7];9(3):787-806. Disponível em: http://revistas.javeriana.edu.co/index.php/revPsycho/article/view/474/586.

8. Bretâs JRS, Ohara CVS, Jardim DP, Aguiar Junior W, Oliveira JR. Aspectos da sexualidade na adolescência. Ciênc Saúde Coletiva. 2011;16(7):3221-8.

9. Dias S, Matos MG, Gonçalves A. Percepção dos adolescentes acerca da influência dos pais e pares nos seus comportamentos sexuais. Anál Psicológica [Internet]. 2007 [acesso em 2013 fev 21];25(4):625-34. Disponível em: http: / /www.scielo.gpeari.mctes.pt/scielo.php?script=sci_arttext\&pid=S0870-

$82312007000400008 \& \operatorname{lng}=$ pt\&nrm=iso.

10. Araújo AC, Lunardi VL, Silveira RS, Thofehrn MB, Porto AR, Soares DC. Implicações da sexualidade e reprodução no adolescer saudável. Rev RENE. 2012;13(2):437-44.

11. Fonseca AD, Gomes VLO, Teixeira KC. Percepção de adolescentes sobre uma ação educativa em orientação sexual realizada por acadêmicos (as) de enfermagem. Esc Anna Nery Rev Enferm. 2010;14(2):330-7.

12. Gonçalves RC. Concepções dos pais acerca do diálogo sobre sexualidade na adolescência. Enciclopédia Biosfera (Centro Científico Conhecer). 2012;8(15):2053-67.

13. Minayo MCS. O desafio do conhecimento: pesquisa qualitativa em saúde. 12a ed. São Paulo: Hucitec; 2010. 407 p.

14. Gadotti M. Concepção dialética da educação: um estudo introdutório. 15a ed. São Paulo: Cortez; 2006.

15. Fontanella BJB, Luchesi BM, Saidel MGB, Ricas J, Turato ER, Melo DG. Amostragem em pesquisas qualitativas: proposta de procedimentos para constatar saturação teórica. Cad Saúde Pública. 2011;27(2):389-93.

16. Bardin L. Análise de conteúdo. 4a ed. Lisboa: Edições 70; 2011. 280 p.

17. Souza TA, Brito MEM, Frota AC, Nunes JM. Gravidez na adolescência: percepções, comportamentos e experiências de familiares. Rev RENE. 2012;13(4):794-804. 


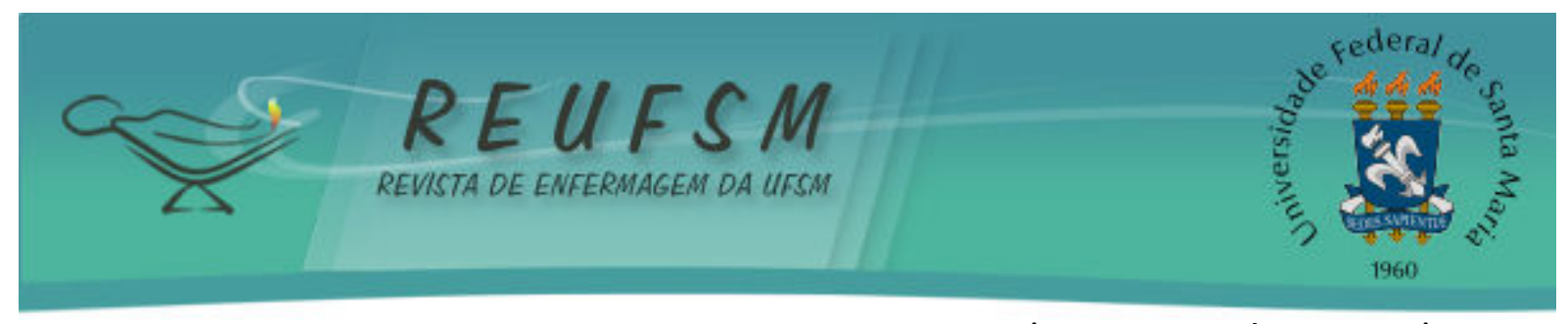

18. Ressel LB, Junges CF, Sehnem GD, Sanfelice C. A influência da família na vivência da sexualidade. Esc Anna Nery. 2011 abr-jun;15(2):245-50.

Data de recebimento: $31 / 07 / 2013$

Data de aceite: 25/10/2013

Contato com autor responsável: Elen Menezes

Endereço postal: Rua Sebastião Gonçalves Coelho, 400, Bloco D, Chanadour. Divinópolis. Minas Gerais - CEP 35.501-296

E-mail: elenmenezesc@gmail.com 